Matthew D. Segall

\title{
Time and Experience in Physics and Philosophy: Whiteheadian Reflections on Bergson, Einstein, and Rovelli
}

\section{Abstract}

This paper begins by revisiting the intellectual collision between Bergson and Einstein. Their crucial misunderstanding almost a century ago did not create but has exacerbated the modern bifurcation between natural science and human experience. After trying to help Einstein and Bergson understand one another, the process-relational cosmology of Alfred North Whitehead is introduced in an effort to articulate an alternative approach to healing the split between physics and experience. While Whitehead affirmed much of Bergson's critique of scientific materialism, he did not entirely share Bergson's views on temporality and departed in critical respects from the Frenchman's vitalism. Finally, Whitehead's cosmology is compared with Carlo Rovelli's Loop Quantum Gravity model of spacetime. Instead of attempting to philosophically explicate scientific formalisms or synthesize mathematics and ontology, I invite these thinkers into dialogue around a question-"What is time?" - that cannot be properly addressed by any one discipline, as it requires us to generate and inhabit an intermediary zone between physics, philosophy, and common sense

\section{Introduction: Whose Time Is It?}

What is time? On the one hand, it appears to be an obvious fact of my everyday experience, and yet, on the other hand, with the slightest reflection upon its nature, I find it dissolves through my fingers into an ageless mystery. The ensuing effort to grasp and articulate time's meaning stretches my imagination in several directions simultaneously. I turn inward as my personal stake in existence leads me to consider the time of my own most direct and intimate experience of being alive. Time is who I am. I was born, I age, and I will die, necessarily in that biological order. Each year, I watch as winter frost melts to make way for spring flowers. Time is the gradual accretion of value, the lure of possibility and the memory of failures and achievements. Time is the emergence of order and pur- 
pose amidst chaos and despite death. Time goads me onward as it gnaws into the future, swelling as it advances (Bergson 1965, 62).

I turn outward as my fascination with fundamental physics leads me to ponder the paradoxes of Relativity and quantum theories. I wonder what, if any, significance my personal biography has given the radically non-teleological and time-reversible determinism intrinsic to most scientific models of Nature. I consider the possibility that my experience of seasonal rhythms is reducible without remainder to the mechanical effect of a slight tilt in the rotation of our dust mote planet as it revolves in warped spacetime around a massive sphere of radiating plasma. Is time just an illusion of aimless relative motion?

I spin inward again as my incurable philosophical itch compels me to search for some more general metaphysical scheme or wider interpretive context within which the laws of physics might find a place alongside lived experience. Physicists, theologians, entrepreneurs, philosophers, artists-really all thoughtful human beings-have at one point or another been struck by this question and struggled to answer it in their own terms. Nearly a century ago, time was at the center of Einstein and Bergson's brief debate in Paris. Centuries earlier, another influential intellect, Benjamin Franklin, had tried to settle accounts: time is money. Centuries earlier still, Augustine had to confess that he did not know what time is (though he offered some potent conjectures). And Plato, as he stared in wonder at the stars above him while inwardly contemplating the perfections of geometry, offered at least a likely story: Time is "a moving image of eternity".

The passage of time is both inescapably obvious and profoundly mysterious. Nothing gets to the heart of who and what we are more than time. Stars ignite, burn their atomic fuel, and go supernova, creating the heavier elements needed for conscious lifeforms to take shape. Dinosaurs go extinct. Radioactive isotopes of carbon in their fossilized remains decay at regular intervals, leaving molecular memories for paleontologists to date their deaths. Human beings decide to take action in the present and regret mistakes made in the past. Civilizations rise and fall. None of these processes is intelligible in reverse. And yet, there has been a strong consensus among physicists for at least a century that the time of human experience, let us call it phenomenological or lived time, is, as Einstein once put it, a "stubbornly persistent illusion". In the equations of physics-whether classical, relativistic, or quantum-it doesn't matter which direction time flows, if it can even be said to "flow" at all. The one exception, perhaps, is the second law of thermodynamics, to which I return later.

As if these scientific notions of time are not strange enough already, the meaning of everyday time is also not at all what it at first appears to be. As Augustine admitted, time is plain as day until someone asks us to explain how it 
works: suddenly, we find ourselves wandering in the dark. A recent New York Times article chronicled the growing controversy (and confusion) about seasonal changes in clock-time, so-called "daylight savings" time (Johnson 2019). Back in the 1920s, changes to local clock-times in US cities like Boston and Detroit led some residents to worry that an extra hour of sunlight in the evening would dry up their gardens and disturb their farm animals. The article quotes author Michael Downing:

The idea of losing or gaining an hour is itself such a fantastically bad philosophical proposition that nobody knows what they're talking about...Most people don't even understand whether moving the clocks forward gives them more sunlight or less sunlight in the morning. They just can't remember what it does, because it so defies logic (Johnson 2019).

In the paper to follow, I offer not a definitive disambiguation of the variety of time conceptions but merely a few potential pathways through the thicket in the hopes of finding some new perspectives on a very old question. I begin by revisiting the intellectual collision between Bergson and Einstein. Their crucial misunderstanding almost a century ago did not create but has exacerbated the modern bifurcation between natural science and human experience. This bifurcation was inaugurated by the new mechanical philosophy of Descartes, Galilei, and Newton, and was later intensified by Kantian transcendentalism. After trying to help Einstein and Bergson understand one another, I turn to the process-relational ontology of Alfred North Whitehead in an effort to articulate an alternative approach to healing the split between physics and experience. While Whitehead affirmed much of Bergson's critique of scientific materialism, he did not entirely share Bergson's views on temporality and departed in critical respects from the Frenchman's vitalism. Finally, I compare Whitehead's ontology to Carlo Rovelli's Loop Quantum Gravity model of spacetime. Instead of attempting to philosophically explicate scientific formalisms or synthesize mathematics and ontology, I invite these thinkers into dialogue around a question- "What is time?" - that cannot be properly addressed by any one discipline, as it requires us to generate and inhabit an intermediary zone between physics, philosophy, and common sense. While the convergence between Rovelli and Whitehead is by no means complete, there are some hopeful signs of alignment that bring us closer to a philosophical reconciliation between our conscious experience and the Nature known to science. 


\section{Einstein and Bergson: The Clash between Physics and Philosophy}

The canonical interpretation of the 1922 debate that the present volume is meant to revisit is that Einstein, the mathematical physicist, won out over Bergson, the philosopher, by dismissing any role for the latter's special faculty of intuition in cosmological investigations. This view of what happened has had lasting consequences for how the general public understands the relationship between scientific knowledge and human experience. While at the time, Bergson's position may have been a contributing factor in the Nobel Prize committee denying Einstein the award for his Relativity theory (the committee officially granted him the prize in 1922 for the photoelectric effect - Clark 2012), by 1945, the standard view was cemented by Bertrand Russell's widely read A History of Western Philosophy, wherein Russell challenged Bergson's understanding of mathematics and dismissed his philosophy as "anti-intellectual” (Russell 1972, 803). This triumphalist interpretation continued to echo in the Science Wars of the mid-1990s, when Sokal and Bricmont published their book Intellectual Impostures (1998), which devoted an entire chapter to the debate between Bergson and Einstein in the French edition.

As more sympathetic interpreters have recently made clear, ${ }^{1}$ contrary to the canonical interpretation it must be remembered that Bergson had no qualms with Einstein's mathematical logic or with the empirical data supporting it. Bergson accepted the epistemological importance of Einstein's Relativity physics and conceived of his own intuitive philosophy not as a competitor but as a metaphysical supplement. Einstein, on the other hand, rejected the metaphysical importance of Bergson's philosophy, dismissing it as a subjective psychological illusion. Bergson's main point of contention with Einstein concerned whether Relativity theory tells us more about the behavior of clocks than it does about concrete or lived time. For Bergson, the vital energy and creative metamorphosis of lived time will always remain invisible to the spatializing methods of scientific measurement and mathematical representation. For Einstein and his inheritors, the invisibility to their methods of Bergson's so-called "lived time" signals only its nonexistence. The philosopher's time does not exist, Einstein insists.

Bergson's refusal to accept Einstein's dismissal as the final word on real time does not mean he denies the practical utility of Relativity theory's spatialization

1 See e.g., Dusek (2000); Čapek (1973); Latour (2011); Canales (2015); White (2015); Sherman (2020). 
of time. Clearly the measurements and models of twentieth century physics have produced amazing technological advances that have transformed human life and society. Einstein came of age just as newly erected train tracks and steam engines began to criss-cross the European landscape, forever warping the time-consciousness of pre-industrial people. Trains linked cities and towns across the continent at faster speeds than ever before. The newly linked stations needed to invent evermore ingenious ways of synchronizing their clocks in order to avoid collisions and remain on schedule. As is well known, prior to becoming the world's most famous scientist Einstein worked as a patent clerk reviewing the latest signaling technologies to assist in establishing the (at least approximate) simultaneity of clocks across long distances. In today's globally interconnected and increasingly digitized world, this convenient way of measuring time has become nearly all-encompassing. All of us have been swallowed alive by mechanical clock-time, our forms of life remodeled to fit its precisely calculated tempo. The daily and seasonal rhythms of Sun, Moon, and stars have faded away into the background of our electrified routines. It is, in Charles Dickens' words, "as if the sun itself had given in" to the ordering power of clocks and the network of machines they coordinate (Dickens 1848, 86). A convenient tool has thus become our master.

Bergson believed that an intuition of lived time is necessarily presupposed in all the physicist's intellectual operations, including his mathematical reflections and empirical measurements. Einstein, on the other hand, regarded Bergsonian intuition as an illusory artifact of our human perception and thus as irrelevant to the objective truths revealed by physics. ${ }^{2}$ For Einstein and the physicists who inherit his way of thinking, there simply is no such thing as a "philosopher's time", that is, the living duration through which evolution continually generates novel forms, as Bergson might say. Instead, Einstein distinguished two kinds of time: psychological time, which is a subjective illusion generated by relative motion, and physical time, which is an objective quantity measured by clocks (that ultimately reduces to a four-dimensional block universe wherein all time exists eternally because no scientifically relevant distinctions can be made between past, present, and future). Given the geometry of his four-dimensional spacetime block, Einstein's can only be a deterministic universe with no room left for divine

2 This despite the fact that Einstein had his own rather Spinozist conception of the role of intuition in divining the laws of physics. The problem, as is unpacked later in this chapter, is that Einstein's bifurcated view of Nature leaves us without any coherent conception of how the intuitive human mind arises out of and comes to be linked up with the mathematical patterns underlying visible Nature. If nature is the deterministic system Einstein imagines it to be, there really should be no room left over for a conscious organism like us to intuit anything. 
dice rolls, creative evolution, or real becoming. The future is just another location in the already actualized block, such that everything has, in a sense, always already occurred. Nothing is held in reserve or in potentia. In light of Bergson's critique of modern science's cinematographical method, it becomes apparent that Einsteinian physics forces us to imagine "time unrolled in space" (Bergson 1913, 342), as if the whole history of life on earth and the becoming of our universe were already recorded on a cosmic movie reel that is collecting dust in heaven's eternal film archive.

Like all modern scientists since Galilei, rather than situating scientific theory and experiment within human experience as one of the latter's possible modes of relation to cosmic reality, Einstein opposed his theoretical model of spacetime to our experience of being alive. The existence of conscious humans or any life form is thus deemed irrelevant to our understanding of the wider universe. Though Bergson said the following of Kant's transcendental philosophy, it could just as easily have been said of Einstein's gravitational epistemology:

Knowledge is presented to us in it as an ever-open roll, experience as a push of facts that is forever going on. But...those facts are spread out on one plane as fast as they arise; they are external to each other and external to the mind. Of a knowledge from within, that could grasp them in their springing forth instead of taking them already sprung, that would dig beneath space and spatialized time, there is never any question. Yet it is indeed beneath this plane that our consciousness places us; there flows true duration (Bergson 1913, 361).

\section{Einstein, Whitehead, and Bergson: Divergences and Confluences}

Bergson was not the only early twentieth century philosopher to protest against this sort of greedy reductionism. In Germany, through a sort of re-charged Kantian transcendentalism, Edmund Husserl and Martin Heidegger's phenomenological inquiries undermined the epistemic and existential ground of scientific materialism. But the anti-naturalistic attitude of especially Heidegger leaves us with a rather intensely anthropocentric understanding of reality, where all non-humans are "poor" or entirely lacking in "world” (Heidegger 1995, 96). In England, Whitehead began articulating an alternative philosophy of Nature, which was neither transcendentalist nor naively realist. He attempted to avoid the abstract and false division between transcendental idealism and reductionistic materialism by diagnosing and healing the metaphysical incoherence he called the 'bifurcation of Nature'. While he would eventually leave his home country and travel to Harvard to take up the philosophical task of constructing a fully-fledged 
metaphysical cosmology, it was Einstein's Relativity theory that first drew Whitehead out of his early work on the foundations of mathematics and into the philosophy of Nature. While Whitehead praised Einstein for the relativistic paradigm shift he played a major role in initiating, he did not accept Einstein's identification of a curved geometrical manifold with the physics of gravitation. Further, like Bergson, he did not accept the implicitly metaphysical interpretation that Einstein attached to his theory. Whitehead wanted to save Einstein's brilliant advance in physics from Einstein's incoherently bifurcated metaphysics.

In his 1919 book An Enquiry Concerning the Principles of Natural Knowledge, Whitehead began to re-imagine the scientific conception of Nature in organic process-relational rather than materialistic substance-property terms. He argues that we must give up the attempt to "conceive of events as in a given Time, a given Space, and consisting of changes in given persistent material”. Instead, we must come to see that "Time, Space, and Material are adjuncts of events". "On the old theory of Relativity" he continues, "Time and Space are relations between materials; on our theory they are relations between events" (Whitehead 2011a, 25-26).

In his 1920 book The Concept of Nature, Whitehead elaborates on his new event ontology by clarifying that space and time "are each partial expressions of one fundamental relation between events which is neither spatial nor temporal" (Whitehead 1920, 185). He calls this relation "extension". Instead of the old theory of material particles as relata for spatial relations, Whitehead posits concrete events as the relata of an ultimate but abstract "Extensive Continuum", a notion that he does not fully work out until Part IV of Process and Reality. In the old conception, bits of matter were imagined as simply located points that are fully present at an instant, with Minkowskian geometrical spacetime intervals providing their systematic relations. In Whitehead's new conception, material particles are replaced by events of various spatiotemporal extents, with nonmetrical mereotopological relations of congruence providing their systematic relations.

In his 1922 book The Principle of Relativity, Whitehead explicitly rejected Einstein's bifurcation of Nature into "psychological time which is personal and impersonal time as it is in nature" (Whitehead 1922, 66). He also claimed to have uncovered a significant logical contradiction in Einstein's philosophical account of Relativity that, if left unaddressed, threatened to undermine the possibility of spatial measurement (Auxier and Herstein 2017, 99 ff). In short, if Einstein's hypostatization of a four-dimensional geometrical manifold is to be believed and spacetime really is a hyper-dimensional "fabric" warped by the presence of massive objects, then the accurate measurement of astronomical distances would require precise and complete knowledge of the distribution of all masses in the 
universe. The problem is that this knowledge cannot be gained in advance of measurement, so we are left having to know everything before we can know anything.

It is important to note that the measurement problem articulated by Whitehead is not just an unpleasant practical consequence of a theoretical advance, but a logical inconsistency that undermines the very possibility of accurate empirical measurement. ${ }^{3}$ Einstein briefly mentions issues of spatial measurement raised by General Relativity in a 1921 paper Geometry and Experience, but he does not appear to believe they represent a problem worth dwelling on, much less a fundamental contradiction in his interpretation of Relativity (Northrop 1931, 113-114). In a 1923 paper on the cosmological implications of his theory, he admits that a consequence of allowing the metrical character or curvature of spacetime to be determined at every point by the matter at that point is that this spacetime must be extremely complicated. But he claims that the possibility of accurate cosmological measurement is saved so long as we believe that matter remains "uniformly distributed over enormous spaces" (Einstein 2013, 183). Whitehead was not convinced. "I cannot understand", he wrote in his book on Relativity:

what meaning can be assigned to the distance of the sun from Sirius if the very nature of space depends upon casual intervening objects which we know nothing about. Unless we start with some knowledge of a systematically related structure of spacetime we are dependent upon the contingent relations of bodies which we have not examined and cannot prejudge (Whitehead 1922, 58-59).

To avoid what he believed was a serious problem, Whitehead built on his new event ontology to develop a set of empirically equivalent tensor equations that did not rely upon the idea of a contingently curved spacetime geometry to explain gravitational effects. Instead, he elaborated a scheme wherein space retained a uniform structure, thereby permitting the projective relations of congruence required for accurate measurement (Whitehead 1978, 332). In place of Einstein's non-uniform spacetime fabric, Whitehead offered his own theory of the propagation of gravitational potential in terms similar to electromagnetic waves, only now gravitational and electromagnetic activity was vibrating in an ether of events rather than the old material ether. In this way, Whitehead was ac-

3 Whitehead traces the root of the measurement problem back to Euclid, who he argues did not properly define a straight line. To say that a straight line is the shortest distance between two points is to base what should be a logical definition of "straightness" on an empirical measurement of "shortest distance" (Whitehead 1978, 303). 
tually able to move physics closer to the unified field theory that Einstein spent the second half of his life searching for, but only by shifting from material points to creative events as fundamental to physical ontology. ${ }^{4}$ The radical implications of the shift to an event (or process-relational) ontology led the physics community to reject Whitehead's approach, at least until quite recently (McHenry 2015, $139-140$; 413n6). For one thing, accepting the fundamental nature of creative events means letting go of the quest for objective certainty that has plagued modern science since its inception. Unlike the standard conception of particles as simply located at a point in space and fully present at an instant in time, events are overlapping, have fuzzy spatial and temporal boundaries, and thus only submit to approximate measurement (McHenry 2015, 44). ${ }^{5}$ Furthermore, events are "creative" in the sense that they emerge from antecedents and contribute themselves as novel ingredients to the ongoing genesis of a openended world-in-process. Temporal extension is thus not a simple succession of instants but a complex process of derivation and accumulation.

An event ontology is also at the center of Whitehead's attempt to heal what he termed "Bifurcation of Nature" (unpacked below), as the gap between the durational unfolding of an electromagnetic event and a moment of conscious experience is far easier to leap than is that between inner experience and extended matter. The former is merely a difference in degree or intensity, while the latter is an ontological chasm reminiscent of Descartes' substance dualism. ${ }^{6}$ While Einstein definitively rejected the Newtonian theory of absolute space in favor of a relational model, Whitehead goes further by re-interpreting Relativity theory within the context of a fully relational epistemology and ontology. Whereas Einstein and the physicists who inherit his way of thinking view our experience as though we are spectators gazing in upon the world from outside it, as though the phenomenological quality of lived time is just a distorted projection onto otherwise objective physical happenings, Whitehead embeds experience within the

\footnotetext{
4 See McHenry (2015).

5 Einstein's Relativity physics builds on the work of predecessors to unite space and time with the mathematical notion of a spacetime interval. Though post-Einsteinian physicists refer to "events" in spacetime, this notion is not sufficiently relativistic from a Whiteheadian point of view. It still has the residue of the old geometrical point-instants, as these "events" are still imagined as though they were simply located within a pre-given fabric.

6 Space limitations for this chapter do not permit a fuller treatment of Whitehead's method of extensive abstraction by which so-called "primary characteristics" are derived from concrete experience, or his theory of perception in terms of three modes, "Presentational Immediacy", "Causal Efficacy" and the integration of these in "Symbolic reference". See his Symbolism: Its Meaning and Effect (1927) for a fuller account of the relationship between concrete experience and the constructs of science.
} 
world as a relational participant essential to shaping its ongoing creative advance. How, then, does Whitehead's critique and reconstruction of Einsteinian physics stand in relation to Bergson's view?

There is a rich literature trying to sort out the extent and nature of Bergson's influence upon Whitehead. Whitehead's biographer Victor Lowe downplayed the significance of the influence, while more recent scholarship by Randall Auxier, Pete Gunter, and Carl Hausman has amplified their relation by arguing for a deep confluence of ideas (1999). According to Whitehead, the measured clocktime of the physicist and of conventional civilized life "merely exhibits some aspects of the more fundamental fact of the passage of nature". On this point Whitehead claims he is in "full accord with Bergson" (Whitehead 1920, 54). Bergson took notice, writing that Whitehead's Concept of Nature "is certainly one of the most profound [works] ever written on the philosophy of nature" (Bergson 1965, 62ff8). Almost a decade later, Whitehead affirmed in Process and Reality that "the history of philosophy supports Bergson's charge that the human intellect 'spatializes the universe'; that is to say, that it tends to ignore the fluency, and to analyze the world in terms of static categories" (Whitehead 1978, 209). But, continues Whitehead, "Bergson went further and conceived this tendency as an inherent necessity of the intellect. I do not believe this accusation" (Whitehead 1978, 209). In the preface to the same book, Whitehead says he was lured into his adventure in cosmology in part to save Bergson's "type of thought from the charge of anti-intellectualism, which rightly or wrongly has been associated with it” (Whitehead 1978, xii).

According to Gunter, Whitehead is not reacting to Bergson's true view in these excerpts. Bergson is not anti-intellectual and does not believe the scientific intellect is inevitably mechanistic and bound to falsely spatialize the universe in all its attempted explanations. In L'Évolution Créatrice (1907), Bergson himself attempted to initiate an organic reformation of the abstractions of science. Whitehead's philosophy of organism can be understood to have brought this project closer to fruition. Nonetheless, Whitehead's and Bergson's respective views do seem to diverge on certain key metaphysical issues. Whether this is a divergence of emphasis or of substance is difficult to decide, since, as Whitehead reportedly remarked during a lecture at Harvard, while Bergson must be praised for writing so evocatively about what he "feels and sees", he must also be faulted for "[phrasing] it so that you never can be quite sure what he means" (Whitehead 2017, 299).

One of Whitehead's apparent divergences from Bergson concerns the Frenchman's emphasis upon the continuity of becoming. In contrast, by the mid-1920s, Whitehead had come to affirm an atomic or epochal theory of the "becoming of continuity" (Whitehead 1978, 35). Lowe (1949, 283) argues this is an 
irreconcilable difference, while Gunter (1999) and Čapek (1973, 120) insist that the divergence is only a difference of emphasis. The latter two thinkers point out that Bergson's duration was no simple continuity, but a multiplicity of overlapping rhythms. As Bergson describes his view in Duration and Simultaneity (1922), duration is "multiplicity without divisibility and succession without separation” (Bergson 1965, 44). While admitting some ambiguity due to Bergson's shifting positions across more than thirty years of writing on the topic, Elie During argues that Whitehead's epochal theory of becoming is systematically circumvented by Bergson's insistent isolation of a "pure experience of time" from the concept of space that is abstracted from it (During 2008, 269; 272; $277 \mathrm{ff11}$ ).

Whitehead's epochal theory of the becoming of continuity rejects both the metaphysical fairy tale of "nature at an instant" (which is still residual even in Einstein's notion of the relativity of simultaneity) and the idea that time is simply an unbroken homogeneous flow. Instead, Whitehead took note of the discontinuity evident in the new quantum theory, which aligned well with his philosophical inheritance of William James' notion of a concrete time that grows drop-wise, by discrete pulses of perception (James 1920, 232; Čapek 1973, 140). In Whitehead's mature philosophy, our experience of apparently continuous becoming is thought to be composed of historical routes of "Actual Occasions of Experience" that each arise from the settled past to achieve their subjective aim in the present before superjectively ${ }^{7}$ perishing into the future, whence they are resurrected by subsequently concrescing occasions. Concrescence is a phasic process but it does not occur "in" an already actualized geometrical spacetime continuum. Rather, Whitehead describes a universe wherein vast societies of electromagnetic and gravitational occasions are actively weaving and reweaving the fraying fabric of spacetime as a field of potential relationship. As was mentioned earlier, Whitehead views space and time as abstractions from concrete events. The events and occasions of experience that they contain are concretely actual, while spacetime is the abstract field of their potential relations. Whitehead calls this field of potential "the extensive continuum" (Whitehead 1978, part IV).

Some Bergsonians may be tempted to view Whitehead's epochal theory of spacetime as another intellectual falsification of living duration. But White-

\footnotetext{
7 Whitehead coins the term "superject" to distinguish the futural phase in the process of concrescence: occasions of experience are said to arise from the objective data of their past, to unify this data in a subjective form, and then to perish into "objective immortality" as "superjects", at that point serving as new data for the next round of concrescence. Each occasion thus arises from its past objectively, experiences itself in the present subjectively, and aims at its future superjectively.
} 
head's understanding of spacetime as epochal is not another cinematographic model of reality, where juxtaposed instants are translated into a cartoon-like illusion of the creative flow and musical rhythm of our inner life. Whitehead affirms the reality of a continuous transition between occasions of experience, but because his speculative scheme is an effort to reform the scientific intellect so that it acknowledges the evidences of intuition, he asks us to imagine another fundamental form of process alongside that of transition: namely, the atomic process of concrescence. Reality can be conceived of as continuous in the social coordination achieved by transitions between actual occasions of experience, which though they each atomize the continuum nonetheless remain linked together in an abstract field of real potentiality. Reality can also be conceived of as epochal, as the given facts established by past actual occasions are taken up into each newborn drop of experience, wherein through some creative intervention upon the past a novel actualization of value is achieved, which then perishes to gift its unique value-intensity back to the cosmic community. There is continuity and there is individuality.

Concrescence is thus a process whereby "the many become one and are increased by one" (Whitehead 1978, 21). There is established, through the synthesis of inherited public feelings and anticipatory private aims, a cumulative movement or creative evolution from past to future along multiple more or less overlapping historical routes of experience. ${ }^{8}$ There is a becoming of continuity rather than a continuity of becoming in this iterative growth process, which is achieved occasion by occasion through individuating acts of valuation. The spacetime continuum, like living organisms, thus grows in a cellular way. As Whitehead put it:

Time and space express the universe as including the essence of transition and the success of achievement. The transition is real, and the achievement is real. The difficulty is for language to express one of them without explaining away the other (Whitehead 1968, 102).

Their possible divergences aside, Whitehead shared with Bergson the desire to re-imagine the relationship between philosophy and science so that the latter would no longer succumb to the temptation of "heroic feats of explaining away” (Whitehead 1978, 23). Whitehead's response to Einstein's reductionistic

8 It is important to note that, in order to overcome the incoherencies of the bifurcated image of Nature, Whitehead found it necessary to borrow some terms usually thought to be applicable only at human scales and to generalize their meaning for use in a now radically non-anthropocentric cosmology. Whitehead's metaphysics of concrescence thus repurposes terms-like "experience", "society", "public" and "private"-so that they apply at all scales of reality. 
metaphysical interpretation of the physics of spacetime was really aimed at a philosophical postulate that long preceded Einstein: the so-called "Bifurcation of Nature” first articulated by Galilei in the seventeenth century. In Galilei's terms, this bifurcation was a division between primary quantitative or material characteristics and secondary qualitative or mental characteristics of reality. This bifurcation is the founding metaphysical gesture of modern scientific materialism. For centuries, it proved to be a tremendous boon to natural scientific investigation, freeing researchers from Scholastic metaphysics by encouraging parsimonious explanations based in empirical measurement and mathematical calculation. But as with all abstract models meant to capture some aspect of concrete reality, its limits are eventually reached and must be understood and accepted. While immensely useful for describing the widespread regularities and settled facts of physical Nature, the bifurcation between primary and secondary characteristics not only severely handicapped enquires into fundamental ontology, it also distorted the biological, psychological, and sociological sciences, where the role of perceptual evaluation and conscious decision-making can no longer be bracketed from relevance.

Disturbed by Einstein's dismissal of the place of consciousness in the cosmos ("For us believing physicists, the distinction between past, present, and future is only an illusion, even if a stubborn one" -Einstein 1972, 537-538), Whitehead realized he needed to challenge this founding metaphysical gesture and search for a more adequate scientific world view. In Whitehead's new organic philosophy of Nature, human perception and agency come to be understood as especially intense expressions of rather than miraculous exceptions to the more habit-bound vibratory rhythms of the physical universe. Replacing the old gesture of bifurcation, Whitehead offers the following founding proposition for a new kind of natural philosophy to undergird physics:

For natural philosophy everything perceived is in nature. We may not pick and choose. For us the red glow of the sunset should be as much part of nature as are the molecules and electric waves by which men of science would explain the phenomenon. It is for natural philosophy to analyze how these various elements of nature are connected (Whitehead 1920, 29).

I quote Whitehead at length on this issue, as it is central to his criticism of scientific materialism's attempt to explain away time:

In making this demand [that everything perceived is in nature], I conceive myself as adopting our immediate instinctive attitude towards perceptual knowledge which is only abandoned under the influence of theory. We are instinctively willing to believe that by due attention, more can be found in nature than that which is observed at first sight. But we will 
not be content with less. What we ask from the philosophy of science is some account of the coherence of things perceptively known. ... What I am essentially protesting against is the bifurcation of nature into two systems of reality, which, in so far as they are real, are real in different senses. One reality would be the entities such as electrons which are the study of speculative physics. This would be the reality which is there for knowledge; although on this theory it is never known. For what is known is the other sort of reality, which is the byplay of the mind. Thus, there would be two natures, one is the conjecture and the other is the dream (Whitehead 1920, 29-30).

Healing the bifurcation of Nature allows natural philosophy to avoid committing what Whitehead called "the Fallacy of Misplaced Concreteness", which is what Einstein falls prey to when he dismisses lived experience as a dream and falsely concretizes a conjectured geometrical model as though it was the final word concerning actual Nature and the potentials relevant to it. Of course, as the history of modern science has made evident, appearances are often deceiving. Taking lived experience seriously doesn't mean accepting reality as it first appears to us. The Earth is not flat and is not orbited by the Sun. As Whitehead says in the excerpt above, we instinctively search for deeper realities and are not satisfied with superficial appearances. There is always more than what at first meets the eye. But the dismissal of our lived experience of temporal becoming in favor of an atemporal theoretical model asks us to accept that Nature is less than our experience reveals. To dismiss lived time would be to lose the thread of experience that makes scientific reflection and experimentation possible in the first place.

Even the mind-bending paradoxes of contemporary theoretical physics are, according to Latour, "child's play in comparison with the multiplicity and complexity of the dimensions that are simultaneously accessible to the most minimal experience of common sense" (Latour 2012, 120). Inheriting the protests of Bergson and Whitehead, Latour invites us to return from outer space to re-inhabit the solid ground of our commonsense experience. The interlacing ecological complexity of our everyday experience of standing on earth beneath the sky, enveloped within an atmosphere alongside many millions of unique species of organisms and other human beings, makes even the mathematical quantum and relativistic realms of theoretical physics look like toy models in comparison. The world of commonsense experience is even more difficult to fathom than the abstract micro- and macroscopic worlds modeled by physicists, since, as Latour reminds us, the former "has been infinitely less explored than the other!" We have as much to learn from artisans and philosophers as from scientists about the textures of the world we actually inhabit.

By rejecting the bifurcation of Nature, Whitehead is also rejecting the idea that time is merely inner. The defensive move to safely tuck time away within 
the mind, whether transcendental or psychological in orientation, is insufficient, since it leaves the physicist to reduce the objective external universe to a timeless block. While in his response to Einstein's Relativity theory in Duration and Simultaneity (1922), Bergson confusedly presents his theory of duration as a phenomenological defense of "direct and immediate experience", the Bergson of earlier works like Matter and Memory (1896) and Creative Evolution (1907) affirms that duration reaches beyond the subject and is also intrinsic to the evolution of all life on earth and indeed to the unfolding of the physical universe itself. ${ }^{9}$ As Bergson put it in Matter and Memory, there is another pathway open to philosophers after the transcendental critique of experiential time as merely a form of inner intuition: they must "seek experience at its source, or rather above the decisive turn where, taking a bias in the direction of utility, it becomes properly human experience" (Bergson 1991, 184).

Contrary to the misreadings of some Bergsonians who suggest that Whitehead anthropomorphically extends Bergson's élan vital to supposedly inorganic matter, ${ }^{10}$ and like the Bergson of earlier works like Matter and Memory and Creative Evolution, Whitehead's process philosophy attempts precisely such a return to the source to uncover a more primordial form of temporal experience that can no longer be anthropocentrically claimed as the unique province of human or even living beings but which must be understood to infect the universe to some degree at every scale of its actualization, from its simplest to its most complex evolutionary expressions. Whitehead tells us that "the primordial element" of the universe itself is "a vibratory ebb and flow...an...energy, or activity" that is "nothing at any instant" and that "requires its whole period...to manifest itself" (Whitehead 1967, 35). This vibratory activity unfolds through its concrescent phases of passion and action, or prehensive reception and creative expression. Crucially, Whitehead unambiguously rejects the dualism Bergson sometimes slips into by affirming that "ultimate concrete fact is an extended process" (Whitehead 1948, 252). "If you have lost process or lost extension”, he continues, "you know you are dealing with abstraction" (Whitehead 1948, 252). Extension is essentially processual, and process is essentially extensional. This is Whitehead's metaphysical reformulation of a now even more general theory of Relativity.

9 See Bergson (2002); Čapek 1973, 154.

10 See Kelly 2010. Here Kelly ironically complains that twentieth-century philosophers have tended to relate to Bergson by "[latching] onto one or another of [his] articulations of a problem, rather than his reformulations of problems and solutions" (Kelly 2010, 1-2, 18ff5), which is exactly what Kelly does to Whitehead by accusing him of anthropomorphism while ignoring his organic reformulation of the problems of dualistic ontology. 


\section{Whitehead and Rovelli: Reconciling Physics and Philosophy}

The final part of this chapter marks some preliminary connections and divergences between Whitehead's cosmological scheme and the Quantum Gravity theory of Carlo Rovelli. Aside from a few comments here and there scattered across the philosophy blogosphere, ${ }^{11}$ I have found exactly two mentions of a possible Whitehead-Rovelli nexus in academic publications. The first is a frustratingly brief footnote in Epperson and Zafiris' Whitehead-inspired Foundations of Relational Realism, wherein they suggest that Rovelli's Relational Quantum Mechanics is "sufficiently compatible for fruitful conversation" even if the underlying philosophical frameworks turn out to be very different (Epperson and Zafiris 2013, xxff3). The second is in Ronny Desmet's Stanford Encyclopedia of Philosophy entry on Whitehead, where he writes that Rovelli's relational interpretation of Quantum Mechanics is "strikingly Whiteheadian”. I agree with Epperson, Zafiris, and Desmet that many passages in Rovelli's popular works align with the process-relational perspective; but it is not yet clear whether Rovelli has fully overcome the modern bifurcation of Nature.

Loop Quantum Gravity (LQG) is one of a number of competing attempts at a so-called "Grand Unifying Theory" (GUT) of the physical universe. A GUT would integrate the relativistic macrocosm and the quantum microcosm, which since their theoretical inceptions over a century ago remain entirely incompatible as models of the universe. In other words, the reigning theories inherited from twentieth century physics appear to describe two very different cosmoi. The primary challenger for a GUT aside from LQG is string theory (ST), and thus far the latter has garnered the most attention. Rovelli does not shy away from stating that his approach requires "a substantial conceptual revolution...[in]...the basic ontology of [twentieth] century physics" (Rovelli and Vidotto 2015, 18). In short, while ST still describes a fundamental physical ontology composed of material objects (i.e., vibrating strings) "in" a pre-given spacetime, LQG describes a universe wherein "it is the physics of the quantum fields that build up spacetime" (Rovelli and Vidotto 2015, 18). On the face of it, this figure-ground shift sounds similar to Whitehead's process-relational ontology, which describes the emergence of spacetime from a nexus of creative events. But a definitive synthesis between any physical model and a philosophical ontology is not that easy to establish. Synthesis certainly overstates what is possible in such a disciplinary

11 See Edwards (2014). 
exchange. All I can claim to do in the remainder of this chapter is to "pilfer" a few ideas from Rovelli's scientific work (a method During suggests for guiding exchanges between science and philosophy), that is, to "feel for when he's not looking and grab something to bring back home and think about for a while" (During 2017).

Unlike many popular physicists who regularly disparage philosophy (e.g., Neil deGrasse Tyson, Laurence Krauss, Steven Weinberg, and the late Stephen Hawking), Rovelli laments the "narrow-mindedness" displayed by his scientific colleagues when it comes to considering the importance of philosophy for their discipline (Rovelli 2014, 215; 227-228). To be fair, he is equally critical of philosophers who don't heed the lessons of science. Rovelli, like Whitehead, is one of the rare thinkers who is capable of making meaningful connections linking mathematics, theoretical physics, philosophy, and human life more generally. In one of his most recent books, The Order of Time, Rovelli not only lucidly summarizes the latest findings of contemporary physics, including his own quantum gravity theory, he also skillfully weaves these theories together with the philosophical insights of Augustine, Kant, Husserl, and Heidegger (who each thought time had more to do with human nature than with physical nature). Rovelli criticizes some philosophers, like Parmenides, Plato, and Hegel, for allegedly fleeing to eternity in an effort to escape the anxiety time causes us (Rovelli 2017, 173). Heraclitus and Bergson, on the other hand, are criticized for allowing an overly emotional veneration of time to cloud their vision (Rovelli 2017, 174).

In Rovelli's view, contemporary physics has revealed the time of our conscious experience to be, at best, an approximation resulting from our thermodynamically improbable perspective on the universe. Aside from the study of thermodynamics, several centuries of modern scientific investigation at both the quantum and relativistic scales have left us with "an empty, windswept landscape almost devoid of all trace of temporality” (Rovelli 2017, 3). However, Rovelli rejects the standard Einsteinian reductionism just as soundly as Bergson and Whitehead. LQG does away with both Newton's conception of absolute time as well as the "Block Universe" idea often associated with Einstein: "The absence of time does not mean that everything is frozen and unmoving...[forming] a four-dimensional geometry"; rather, Rovelli claims, the world is an "incessant happening ... a boundless and disorderly network of quantum events" (Rovelli 2017, 92). And after recounting the "epic and magical" distortions of time created by the ingestion of cannabis and LSD, Rovelli reminds his readers that "it was certainly not our direct experience of time that gave us the idea" of a purely continuous time passing "at the same rate, always and everywhere" (Rovelli 2017, 53). This is an abstract and relatively recent idea of time reflecting our immersion in a modern civilization ruled over by mechanical clocks. 
Rovelli discusses the heretical view of another philosophically attuned physicist, Lee Smolin, whose recent book with Roberto Unger, The Singular Universe and the Reality of Time (2014, xv), argues forcefully against the scientific consensus and for the fundamental reality of time. Smolin and Unger approvingly cite Whitehead in their introduction as an exponent of the ancient but dissident tradition of becoming in Western philosophy (others mentioned are Heraclitus, Hegel, Peirce, and Bergson). Whitehead shares with Unger and Smolin the conviction that many of the so-called "laws" and "constants" of physics, far from being eternal and necessary, are in fact contingently evolved habits. Rovelli and Smolin were collaborators on LQG for a time and remain friends, but they diverge sharply on the question of time's place in physics. As we've seen, like Whitehead, Rovelli views the gelatinous spacetime continuum as a secondorder emergent property of quantum events (Rovelli 2017, 168). Spacetime, Rovelli says,

has loosened into a network of relations that no longer holds together as a coherent canvas. The picture of spacetimes (in the plural) fluctuating, super-imposed one above the other, materializing at certain times with respect to particular objects, provides us with a very vague vision. But it is the best that we have for the fine granularity of the world (Rovelli 2017, 80).

It is difficult not to hear resonances between Rovelli's projective topological account of the quantum network underlying space and time and Whitehead's notion of the relational complex he called the "extensive continuum" (Whitehead 1978, 66-67). But unlike Whitehead, Rovelli reduces his relational quantum events to mere transitions of "physical quantities from one to another" (Rovelli $2017,168)$, thus robbing them of any experiential quality or explanatory value. Whitehead's actual occasions, in their atomization of the extensive continuum, are not timeless "quanta" mutely crunching an algorithmic program. Occasions are amenable to such quantitative analysis, but in their integral concreteness they are also qualitative expressions of value-experience. Whitehead would likely ask what sense there is in rejecting Newton and Einstein's clock-work universe only to then computerize the cosmos, instead? Whitehead lamented the way "the divergence of the formulae about nature from the appearance of nature has robbed the formulae of any explanatory power" (Whitehead 1968, 154). Whitehead's cosmos is composed not of blind abstract calculations but of social relations among creaturely occasions seeking to intensify their value-experience. These occasions do ingress certain measurable mathematical patterns, but it is the experiential activity that explains the equations, not the other way around.

If Rovelli's theory is not just a convenient model and there is really a network of quantum spin foams at the root of spatiotemporal Nature, Whitehead's 
philosophy of organism requires that there be some aim realized in this spinning, something it feels like to foam, to endure the topological looping, fraying, and folding of these creative quantum events. Physicists searching for a GUT can no longer bracket the existential questions puzzled over by philosophers: Is the lived time of human consciousness in any sense an expression of some more primordial value-experience in Nature? Or is our existence just a peripheral accident, our experiential perspectives just inessential epiphenomena somehow emergent from a blind physical reality? Rovelli appears to take the latter view, giving physical models precedence over lived experience as regards ontology. He rejects views like Smolin's because he believes they lean too heavily on an emotionally charged intuition about time's importance in the physical universe. "The choice"-Rovelli tells us-"Is between forcing the description of the world so that it adapts to our intuition, or learning instead to adapt our intuition to what we have discovered about the world" (Rovelli 2017, 190ff14). Certainly, as we saw earlier, Whitehead affirms the need to "look again" at the world, and to experiment with our perceptions, in order to assure that our ideas and abstract accounts remain in accord with the concrete happenings of actual Nature. But how are we to access concrete reality except through experience or intuition?

Rovelli is careful elsewhere to clearly reject the classical idea of a view from nowhere: "A point of view is an ingredient in every description of the observable world that we make" (Rovelli 2017, 132) and "the world is...a collection of interrelated points of view...there is no 'outside' to the world" (Rovelli 2017, 108). So, while Rovelli's dismissal of the evidences of intuition seems like a re-entrenchment of the bifurcation of Nature between objective science and subjective dream that Whitehead so forcefully protested against, this rejection is out of step with his own broader commitment to a relational reality. Like Einstein, Rovelli stops short of realizing the full ontological import of his relational theory. He thus separates our lived experience from a toy model of the physical world which leaves no room for it. The Bergsonian or Whiteheadian philosopher is left wondering how such a model could be discovered or confirmed if not via experience? Rovelli, by neglecting the relational essence of reality, succumbs to what Auxier and Herstein call "Model-Centric Thinking":

For what are we left with to test our models, other than the formal and recondite cleverness of those models? What standards might we apply to test our models when our model-centric approach demands that we measure experience by those models, rather than those models by experience? (Auxier and Herstein 2017, 111).

According to Whitehead, "the physical world is in some general sense of the term a deduced concept. Our problem is, in fact, to fit the world to our percep- 
tions, and not our perceptions to the world" (Whitehead 1967b, 166). This statement may seem a bit strange coming from a professed realist. But we must not misunderstand Whitehead's meaning. He is, as Auxier and Herstein make clear, a radical empiricist in William James' sense. The universe is relational and esemplastic: it grows from the inside out, each part containing the whole in potentia. Whatever this universe is, it is happening not just out there but right here, right now within and between us. We do not and cannot experience the universe in its integrity as a child observes a snow globe at arms-length. But the "Big Bang model” of inflationary cosmology is often discussed at least in popular science books and by science journalists precisely in this way, as though we were turning the world around in our hand to have a good look at it. Where are we as observers in these acts of cosmological imagination? Precisely nowhere.

If time is an illusion, what sense is there to be made of the history of our universe? Rovelli suggests that our perception of a cosmic evolution through irreversible time results from our perspective at the far end of a thermodynamic heat sink. Inflationary models of the observable cosmos suggest that our world emerged from a very low entropy state at the beginning of the universe and is gradually running down toward heat death. Our vision of the cosmos as such is blurred by our special position in this entropic process. Rovelli writes:

If a subset of the universe is special in this sense, then...memories exist, traces are left and there can be evolution, life and thought...We observe the universe from within [this subset], interacting with a minuscule portion of the innumerable variables of the cosmos. What we see is a blurred image. This blurring suggests that the dynamic of the universe with which we interact is governed by entropy, which measures the amount of blurring. It measures something that relates to us more than to the cosmos (Rovelli 2017, 130; 134).

It is not only our special cosmic position that creates this blurring, according to Rovelli. It is also our special form of biological organization powered by a web of negentropic chemical processes. Life is poised at the cresting wave of a thermodynamic gradient, feeding on light from the Sun and ultimately producing dramatically more entropy than would otherwise be possible on a dead Earth. Whitehead describes the emergence of special "cosmic epochs" from out of the metaphysically generic extensive continuum (Whitehead 1978, 91). While the laws and constants of physics, as well as the metrical properties of spacetime, the particles described by the standard model, and all larger organized bodies like stars, galaxies, planets, plants, and animals, have emerged within our epoch, the extensive continuum's generic topological properties hold across all such epochs. Whitehead thought the properties of this extensive continuum were truly metaphysical or fundamental in nature, much as Rovelli thinks his quantum network is fundamental. 
Whitehead's notion of a cosmic epoch also bears some resemblance to Rovelli's account of thermodynamically improbable subsets of the wider universe. However, Whitehead does not shy away from the sort of speculative ideas that would be necessary for such an account to count as a coherent explanation. While Rovelli is content to explain away basic features of our universe like memory, causation, and the irreversible flow of time as "nothing but names" (Rovelli 2017,147 ) that we give to describe our statistically improbable egress from a low entropy event in the past, Whitehead would agree with Smolin that the fact that such accounts pass as "explanation" is only a "measure of the depth of the current crisis" faced by scientific cosmology (Smolin and Unger 2014, 355). Rather than dismiss the profoundly beautiful forms of complexity achieved by our self-organizing universe as nothing but accidental smudges in the flow of entropy, Whitehead grants reality to a "counter-agency" infusing the physical universe with a tendency toward order (Whitehead 1958, 25).

At this point, many scientists are likely unable to follow Whitehead. Even he admits that this counter-agency "is too vast and diffusive for our direct observation" (Whitehead 1958, 25). But in the course of constructing his speculative cosmology, which seeks to offer a satisfying explanation for the astonishingly organized universe that we directly observe and that produced us as observers, Whitehead found it necessary to make reference to what some contemporary physicists are beginning to call "extropy" (Grandpierre 2012, 73-79). Which is more improbable, that our universe is erotically lured toward organizational complexity, with human consciousness being a natural outgrowth of cosmic evolution, as Whitehead wagers, or, as Rovelli supposes, that the directly observed facts of a time-developmental universe, including everything from physical causation to star and galaxy formation to mental capacities like memory and anticipation, are all just mirages arising from our blurred perspective on an exceedingly rare hot spot at the origin of our subset of the cosmos?

Even if the irreversible temporality of cosmic evolution and human life is not metaphysically fundamental, as both Whitehead and Rovelli agree, this does not mean causality, memory, and purpose are merely nominal. These are real features of an exceedingly creative cosmos, as real as energy, entropy, and indeed, should Loop Quantum Gravity turn out to be correct, as real as spinfoams. According to Whitehead, "the extreme rejection of final causation from our categories of explanation has been fallacious" (Whitehead 1958, 28). A satisfactory cosmology, he insists, must explain the dipolar interweaving of entropy and extropy, of dissipation and organization, without attempting to reduce one to an epiphenomenon of the other. 


\section{Conclusion: Whitehead and the Physics of Experience}

"[The] antagonism between philosophy and natural science has produced unfortunate limitations of thought on both sides" (Whitehead 1958, 61) according to Whitehead. "Philosophy has ceased to claim its proper generality, and natural science is content with the narrow round of its methods" (Whitehead 1958, 61). While the original rejection of Scholastic metaphysics and formulation of the mechanical categories and empirical methods of physical science in the seventeenth century has proven tremendously successful, the advances of the last century and a half (including evolutionary, Relativity, Quantum Mechanics and complexity theories) have brought us into a critical period of general reorganization of the categories of scientific thought. Not only our concept of time, but that of space, matter, life, and mind must all be rethought and brought into new accord. The old mechanical definitions of these terms and their relations are simply no longer relevant. The needed reorganization of fundamental ideas is not a task that natural science can undertake on its own, as should be clear from the fact that after more than a century a coherent integration of Relativity and Quantum theories remains as elusive as ever (though LQG and ST are contenders, major obstacles stand in the way of their widespread acceptance).

Whitehead's philosophy of organism is an effort to construct a new processrelational ontology for natural science to replace the now defunct mechanistic ontology. Time undoubtedly remains as mysterious as ever in Whitehead's organic cosmology, but the bifurcation between its inner mental and outer material aspects is resolved. The passage of Nature does not unfold as a series of instants or snapshots. Such instantaneity can be approached via mathematical abstraction, but actual passage or creative advance is a process that grows from occasion to occasion in networks of relations, not a series of point-instants on a grid. Unlike Bergson's durations, Whitehead's actual occasions of experience are not made of "pure time" but each exist stretched out in a sort of sublime tension, what James called a "Specious Present", wherein the already actualized past is inherited and subjectively integrated with potential futures. The arising and perishing of numberless actual occasions forms what Whitehead calls historic routes or "societies", and it is at this level that what we consciously experience as the flow of time emerges.

This endlessly iterating creative process is the power that builds the cosmos and that shapes the soul. We can think of the cosmic socius of occasions as a complex network of experiential activities, all internally related but also differentiated along multiple timelines. It is difficult for our three-dimensional imag- 
ination to grasp a topological network of activities wherein each node or occasion is both a whole in itself, prehending the entire universe in its concrescence, and a part within the concrescence of other occasions. The universe as a whole thus remains in "essential incompleteness" (Whitehead 2011b, 90) as it is never finished or fully present but always advancing into novelty as "the many become one, and are increased by one" (Whitehead 1978, 21).

\section{References}

Auxier, Randall E. (1999), "Influence as Confluence: Bergson and Whitehead”, in: Process Studies 28 (3-4), 301-338.

Auxier, Randal E./Herstein, Gary L. (2017), The Quantum of Explanation: Whitehead's Radical Empiricism, London.

Bergson, Henri (1913), Creative Evolution, New York.

Bergson, Henri (1965), Duration and Simultaneity: with Reference to Einstein's Theory, La Salle, La Salle, Indianapolis.

Bergson, Henri (1991), Matter and Memory, New York.

Bogaard, Paul/Bell, Jason (eds.) (2017), The Harvard Lectures of Alfred North Whitehead: Philosophical Presuppositions of Science, Edinburgh.

Canales, Jimena (2015), The Physicist and the Philosopher: Einstein, Bergson, and the debate that changed our understanding of time, Princeton, New Jersey.

Čapek, Milič (1973), Bergson and Modern Physics: A Reinterpretation and Re-evaluation, Dordrecht.

Clark, Stuart (2012), “Why Einstein never received a Nobel Prize for Relativity," in: The Guardian (October 8, 2012), https://www.theguardian.com/science/across-the-universe/ 2012/oct/08/einstein-nobel-prize-relativity [accessed December 18, 2020].

Desmet, Ronald (2018), “Whitehead”, in: Stanford Encyclopedia of Philosophy https://plato. stanford.edu/entries/whitehead/\#PhilScie

Dickens, Charles (1848), Dombey and Son, Philadelphia.

During, Elie (2008), “Durations and Simultaneities: Temporal Perspectives and Relativistic Time in Whitehead and Bergson", in: Weber, Michel (ed.). Handbook of Whiteheadian Process Thought, Berlin, 259-282.

During, Elie (2018), "Science and Philosophy”, lecture delivered for the European Graduate School in Saas-Fee, Switzerland on June $18^{\text {th }}, 2017$, https://www.youtube.com/watch?v= h2ZTYIW7TF4, timestamp 15:43.

Dusek, Val. et al (2000). "Clarity, charity and criticism, wit, wisdom and worldliness: Avoiding intellectual impositions", in: Metascience 9, 358-366.

Edwards, Geoffrey (2018), Rethinking time, https://www.infiniteconversations.com/t/rethink ing-time/ 2014

Einstein, Albert (1972), Albert Einstein, Michele Besso, Correspondence, 1903-1955, Paris.

Einstein, Albert (2013), “Cosmological Considerations on the General Theory of Relativity", in: Francis Davis (ed.), Lorentz, Hendrik/Einstein Albert/Minkowski, Hermann/Weyl, Hermann, The Principle of Relativity, New York, 175-188. 
Epperson, Micheal/Zafiris, Elias (2013), Foundations of Relational Realism: A Topological Approach to Quantum Mechanics and the Philosophy of Nature, New York.

Grandpierre, Attila (2012), "Entropy, Extropy and the Physical Driver of Irreversibility”, in: Interdisciplinary Description of Complex Systems 10 (2), 73-79.

Gunter, Pete A. Y. (1999), “Bergson, Mathematics, and Creativity”, in: Process Studies 28 (3-4), 268-288.

Hausman, Carl E. (1999), “Bergson, Peirce, and Reflective Intuition”, in: Process Studies 28 (3-4), 289-300.

Heidegger, Martin (1995), The Fundamental Concepts of Metaphysics: World, Finitude, Solitude, Bloomington, IN.

James, William (1920), A Pluralistic Universe, New York.

Johnson, Kirk (2019), “Daylight Saving Is Here. Suppose We Made This Time Change Our Last?” in The New York Times, March 9, 2019, https://www.nytimes.com/2019/03/09/us/daylight-sa vingstime.html?fbclid=IwAR17AIGToFUvx3PkI_U50Y]16rPjw6OYIWvgHdYIYhg8W_Nu3-4BMrpJ4Js [accessed March 9, 2019].

Kelly, Micheal R. (2010), “Introduction: Bergson's Phenomenological Reception: the Spirit of a Dialogue of Self-Resistance”, in: Micheal R. Kelly (ed.) Bergson and Phenomenology, New York, 1-21.

Latour, Bruno (2012), An Inquiry into Modes of Existence, Cambridge MA.

Lowe, Victor (1949), "The influence of Bergson, James and Alexander on Whitehead", in: Journal of the History of Ideas 10 (2), 267-296.

McHenry, Leemon B. (2015), The Event Universe: The Revisionary Metaphysics of Alfred North Whitehead, Edinburgh.

Northrop, Filmer S. C. (1931), Science and First Principles, Cambridge.

Pearson, Ansell/Mullarkey John O. (2002), Henri Bergson: Key Writings, New York.

Rovelli, Carlo (2014), “Science Is Not About Certainty”, in: John Brockman (ed.), The Universe, New York, 214-228.

Rovelli, Carlo/Vidotto, Francesca, (2015), Covariant Loop Quantum Gravity: An Elementary Introduction to Quantum Gravity and Spinfoam Theory, Cambridge.

Rovelli Carlo (2017), The order of Time, New York.

Russell, Bertrand (1972), The History of Western Philosophy, New York.

Sherman, Jacob H. (2020), "Who speaks for nature? On the continued importance of the Bergson-Einstein debate”, in: Theology and Science 18 (1), 137-151, https://doi.org/10. 1080/14746700.2019.1710354

Smolin, Lee/Unger, Roberto M. (2014), The Singular Universe and the Reality of Time, Cambridge.

Sokal, Alan/Bricmont, Jean (1998), Intellectual Impostures, London.

White, Melanie (2015), “Bergson and Bergsonism: A Reply to Riggio”, in: Social Epistemology Review and Reply Collective 4 (6), 40-44.

Whitehead, Alfred N. (1920), The Concept of Nature, Cambridge.

Whitehead, Alfred N. (1922), The Principle of Relativity with applications to physical science, Cambridge.

Whitehead, Alfred N. (1948), Science and philosophy, New York.

Whitehead, Alfred N. (1958), The Function of Reason, Boston.

Whitehead, Alfred N. (1967a), Science and the Modern World, New York.

Whitehead, Alfred N. (1967b), Space, Time, and Relativity, in: Aims of Education, New York. 
Whitehead, Alfred N. (1968), Modes of Thought, New York.

Whitehead, Alfred N. (2011a), An Enquiring Concerning the Principles of Natural Knowledge, Cambridge.

Whitehead, Alfred N. (2011b), Religion in the Making, Cambridge. 
